\title{
ON COMMON FIXED POINTS OF WEAKLY COMMUTING MAPPINGS AND SET-VALUED MAPPINGS
}

\author{
S. SESSA \\ Istituto di Natematica \\ Facolta di Architettura \\ Universita di Napoli \\ Via Monteoliveto 3 \\ 80134 Napoli, Italy \\ and \\ B. FISHER \\ Department of Mathematics \\ The University \\ Leicester, ENGLAND \\ (Received September 7, 1984)
}

ABS'TRACT. Our main theorem establishes the uniqueness of the common fixed point of two set-valued mappings and of two single-valued mappings defined on a complete metric space, under a contractive condition and a weak commutativity concept. This improves a theorem of the second author.

KEYY WORDS AND PHRASES. Common fixed point, set-valued mapping, weak commutativitu!. 1980 AMS SUBJECT CLASSIFICATION CODES. 54H25, $47 \mathrm{H10}$.

1. BASIC PRELIMINARIES.

Let $(X, d)$ be a complete metric space and let $B(X)$ be the set of all nonempty, bounded subsets of $X$. As in [1], let $\delta(A, B)$ be the function defined by

$$
\delta(A, B)=\sup \{d(a, b): a \in A, b \in B\}
$$

for all $A, B$ in $B(X)$.

If $A$ consists of a single point a we write

$$
\delta(A, B)=\delta(a, B)
$$

and if $B$ also consists of a single point $b$ we write

$$
\delta(A, B)=d(a, b) \text {. }
$$

It follows immediately from the definition that

$$
\begin{aligned}
& \delta(A, B)=\delta(B, A) \geq 0, \delta(A, A)=\operatorname{diam} A, \\
& \delta(A, B) \leq \delta(A, C)+\delta(C, B)
\end{aligned}
$$

for all $A, B, C$ in $B(X)$.

We say that a subset $A$ of $X$ is the limit of a sequence $\left\{A_{n}\right\}$ of nonempty subsets of $X$ if each point $a$ in $A$ is the limit of a convergent sequence $\left\{a_{n}\right\}$, where $a_{n}$ is in $A_{n}$ for $n=1,2, \ldots$, and if for arbitrary $\epsilon>0$, there exists an integer $N$ such that $A_{n}=A_{r}$ for $n>N$, where $A_{f}$ is the union of all open spheres with 
centres in $A$ and radius $\epsilon$.

LEMMA 1. If $\left\{A_{n}\right\}$ and $\left\{B_{n}\right\}$ are sequences of bounded subsets of $(X, d)$ which converge to the bounded sets $A$ and $B$ respectively, then the sequence $\left\{\delta\left(A_{n}, B_{n}\right)\right\}$

converges to $\delta(A, B)$.

This lemma was proved in [2].

Now let $F$ be a mapping of $X$ into $B(X)$. We say that $F$ is continuous at the point $x$ in $x$ if whenever $\left\{x_{n}\right\}$ is a sequence of points in $x$ converging to $x$, the sequence $\left\{\mathrm{Fx}_{n}\right\}$ in $B(X)$ converges to $F x$ in $B(X)$. If $F$ is continuous at each point $x$ in $X$, we say that $F$ is a continuous mapping of $X$ into $B(X)$. A point $z$ in $X$ is said to be a fixed point of $F$ if $z$ is in $F z$.

For a selfmap I of (X,d), the authors of [3], extending the results of [2] and [4], defined $F$ and $I$ to be weakly commuting on $X$ if

$$
\delta(F I x, I F x) \leq \max \{\delta(I x, F x) \text {, diam } I F x\}
$$

for all $x$ in $X$. Two commuting mappings $F$ and $I$ clearly commute, but two weakly commuting mappings $F$ and $I$ do not necessarily commute as is shown in the following example.

EXAMPLE 1. Let $X=[0,1]$, let $\delta$ be the function induced by the euclidean metric $d$ and define

$$
F x=\left[0, x /\left(x+a^{h}\right)\right], \quad I x=x / a
$$

for all $x$ in $x$, where $h \geq 1$ and $a \geq 2$. Then for any non-zero $x$ in $x$ we have

$$
\text { FI }=\left[0, x /\left(x+a^{h+1}\right)\right] \neq\left[0, x /\left(a x+a^{h+1}\right)\right]=I F x
$$

but for any $x$ in $x$ we have

$$
\delta(F I x, I F x)=x /\left(x+a^{h+1}\right) \leq x / a=\delta(I x, F x) .
$$

Note that if $F$ is a single-valued mapping, then the set $\{$ IFx\} consists of a single point and therefore diam $\{I F x\}=0$ for all $x$ in $X$. Condition (1.1) therefore reduces to the condition given in [5], i.e.

$$
d(F I x, I F x) \leq d(I x, F x)
$$

for all $x$ in $x$.

An extensive literature exists about (common) fixed points of set-valued mappings satisfying contractive conditions controlled from non-negative real functions $f$ from $[0, \infty)$ into $[0, \infty)$. Suitable properties of $f$ guarantee the convergence to the (common) fixed point of the sequence of successive approximations: see for example the papers of Barcz [6], Chen and Shih [7], Guay, Singh, and Whitfield [8], Miczko and Palezewski [9], Nhan [10], Papageorgiou [11], Popa [12], Sharma [13] and Wegrzyk [14]. In this paper we consider the family $F$ of functions $f$ from $[0, \infty)$ into $[0, \infty)$ such that

(a) $\mathrm{f}$ is non-decreasing,

$(\alpha \alpha) \mathrm{f}$ is continuous from the right,

$(\alpha \alpha \alpha) f(t)<t$ for all $t>0$.

LEMMA 2. For any $t>0, \lim _{n \rightarrow \infty} f^{n}(t)=0$.

The proof of this lemma is obvious but see also [15]. 
Further details about the usage of functions with properties similar to $(\alpha),(\alpha \alpha)$, and $(\alpha \alpha \alpha)$ can be found in the papers of Benedykt and Matkowski [16], Browder [17], Conserva and Fedele [18], Hegedüs and Szilágyi [19], Hikida [20], Park and Rhoades [21], Rhoades [22], and Singh and Kasahara [23].

2. RESUlTS IN COMPLETE METRIC SPACES.

Let $F, G$ be two set-valued mappings of $X$ into $B(X)$ and let $I$, $J$ be two selfmaps of $X$ such that

$$
\mathrm{F}(\mathrm{X}) \subseteq \mathrm{I}(\mathrm{X}), \quad \mathrm{G}(\mathrm{X}) \subseteq \mathrm{J}(\mathrm{X}) \text {. }
$$

l.et $x_{0}$ (Resp. $y_{0}$ ) be an arbitrary point in $x$ and define inductively a sequence $\left\{x_{n}\right\}$ (resp. $\left.\left\{y_{n}\right\}\right)$ such that, having defined the point $x_{n-1}\left(\right.$ resp. $\left.y_{n-1}\right)$, choose a point $\because_{n}$ (resp. $y_{n}$ ) with $\operatorname{Ix}_{n}$ (resp. $J_{n}$ ) in $F_{n-1}\left(\right.$ resp. $G_{n-1}$ ) for $n=1,2, \ldots$. This can be done since the range of I (resp. J) contains the range of F (resp. (i). Further, assume that

$$
\sup \left\{\delta\left(\mathrm{Fx}_{\mathrm{n}}, \mathrm{Gy}_{0}\right), \delta\left(\mathrm{Gy}_{\mathrm{n}}, \mathrm{Fx}_{0}\right): \mathrm{n}=1,2, \ldots\right\}<\infty .
$$

REMARK 1. IF $X$ is bounded then (2.2) will always be satisfied for all $x, y$ in $x$. We consider the following conditions:

$\left(r_{1}\right)$ I continuous,

$\left(\gamma_{2}\right) \quad F$ continuous and IFx $\cong$ FIx for all $x$ in $x$.

$\left(\lambda_{1}\right) J$ continuous,

$\left(\lambda_{2}\right) \quad G$ continuous and $J G x \subseteq G J x$ for all $x$ in $x$.

Modifying the proof of theorem 1 of [1] we are now able to prove the following: THEOREM 1. Let $F, G$ be two set-valued mappings of $X$ into $B(X)$ and let $I, J$ be two selfmaps of $X$ satisfying (2.1) and

$$
\delta(F x, G y) \leq f(\max \{d(I x, J y), \delta(I x, G y), \delta(J y, F x)\})
$$

for all $x, y$ in $X$, where $f$ is in $F$. Further let $F$ and $G$ weakly commute with $I$ and $J$ respectively. If there exist points $x_{0}$ and $y_{0}$ in $x$ satisfying (2.2) and if the conditions $\left(\gamma_{i}\right)$ and $\left(\lambda_{j}\right)$ with $i, j=1,2$, hold, then $F, G, I$ and $J$ have a unique common fixed point $z$. Further, $F z=G z=\{z\}$ and $z$ is the is the unique common fixed point of $F$ and $I$ and of $G$ and $J$. PROOF. Since

$$
\delta\left(\mathrm{Fx}_{\mathrm{r}}, \mathrm{Gy}_{\mathrm{s}}\right) \leq \delta\left(\mathrm{Fx}_{\mathrm{r}}, \mathrm{Gy}_{0}\right)+\delta\left(\mathrm{Gy}_{0}, \mathrm{Fx}_{0}\right)+\delta\left(\mathrm{Fx}_{0}, \mathrm{Gy_{s }}\right),
$$

it follows from (2.2) that

is finite.

$$
M=\sup \left\{\delta\left(\mathrm{Fx}_{\mathrm{r}}, \mathrm{Gy}_{\mathrm{s}}\right): \mathrm{r}, \mathrm{s}=0,1,2, \ldots\right\}
$$

If $M>0$, then for arbitrary $\epsilon>0$, we can choose an integer $p$ such that $\mathrm{f}^{\mathrm{P}}(\mathrm{M})<\epsilon$ by lemma 2. If $\mathrm{M}=0$, then $\mathrm{f}^{\mathrm{P}}(\mathrm{M})=0<\epsilon$ for any integer $\mathrm{p}$.

As in the proof of theorem 1 of [24], we have on using inequality (2.3) p times and property $(\alpha)$ :

$$
\begin{aligned}
\delta\left(\mathrm{Fx}_{\mathrm{m}}, \mathrm{Gy}_{\mathrm{n}}\right) & \leq \mathrm{f}^{\mathrm{p}}\left(\operatorname { m a x } \left\{\delta\left(\mathrm{Fx}_{\mathrm{r}}, \mathrm{Gy}_{\mathrm{q}}\right): \mathrm{m}-\mathrm{p} \leq \mathrm{r} \leq \mathrm{m} ;\right.\right. \\
& \mathrm{n}-\mathrm{p} \leq \mathrm{q} \leq \mathrm{n}\}) \\
& <\Leftarrow
\end{aligned}
$$


for $m, n>p$. Thus

$$
\delta\left(F x_{m}, F x_{n}\right) \leq \delta\left(\mathrm{Fx}_{m}, G y_{s}\right)+\delta\left(G_{s}, F x_{r}\right)<2 \epsilon
$$

for $m, n>p$. The sequence $\left\{z_{n}\right\}$ is therefore a Cauchy sequence in the complete metric space $X$ and so has a limit $Z$ in $X$, where $z$ is independent of the particular choice of each $z_{n}$. It follows in particular that the sequence $\left\{\mathrm{Ix}_{n}\right\}$ converges to $z$ and the sequence of sets $\left\{F_{n}\right\}$ converges to the set $\{z\}$.

Similarly, it can be proved that the sequence $\left\{\mathrm{Jy}_{n}\right\}$ converges to a point w and the sequence of sets $\left\{\mathrm{Gy}_{n}\right\}$ converges to the set $\{w\}$.

Using (2.3) we have

$$
\delta\left(F x_{n}, G y_{n}\right) \leq \mathrm{f}\left(\max \left\{\mathrm{d}\left(\mathrm{Ix}_{\mathrm{n}}, \mathrm{Jy}_{\mathrm{n}}\right), \delta\left(\mathrm{Ix}_{\mathrm{n}}, G \mathrm{y}_{\mathrm{n}}\right), \delta\left(\mathrm{Jy}_{\mathrm{n}}, \mathrm{Fx_{n }}\right)\right\}\right)
$$

Letting $n$ tend to infinity and using lemma 1 and properties $(\alpha \alpha)$ and $(\alpha \alpha \alpha)$, it is seen that $w=z$.

Now suppose that $\left(\gamma_{1}\right)$ holds. Then the sequence $\left\{I^{2} x_{n}\right\}$ and $\left\{I F x_{n}\right\}$ converge to $I z$ and $\{I z\}$ respectively. Let $w_{n}$ be an arbitrary point in FIx for $\mathrm{n}=1,2, \ldots$. Then since $\mathrm{I}$ weakly commutes with $\mathrm{F}$ we have on using (1.1)

$$
\begin{aligned}
d\left(w_{n}, I z\right) & \leq \delta\left(F I x_{n}, I z\right) \\
& \leq \delta\left(F I x_{n}, I F x_{n}\right)+\delta\left(I F x_{n}, I z\right) \\
& \leq \max \left\{\delta\left(I x_{n}, F x_{n}\right), 2 \delta\left(I^{2} x_{n+1}, I F x_{n}\right)\right\}+\delta\left(I F x_{n}, I z\right) .
\end{aligned}
$$

Letting $n$ tend to infinity and using lemma 1 we see that the sequence $\left\{w_{n}\right\}$ converges to $I z$. But $I z$ is independent of the particular choice of $w_{n}$ in FIx ${ }_{n}$ and this means that the sequence of sets $\left\{\mathrm{FIx}_{\mathrm{n}}\right\}$ converges to the set $\{\mathrm{Iz}\}$.

Using inequality (2.3) we have

$$
\delta\left(F I x_{n}, G y_{n}\right) \leq f\left(\max \left\{d\left(I^{2} x_{n}, J y_{n}\right), \delta\left(I^{2} x_{n}, G y_{n}\right), \delta\left(J y_{n}, F I x_{n}\right)\right\}\right) .
$$

Letting $n$ tend to infinity and using lemma 1 and property $(\alpha \alpha)$, we have

$$
\mathrm{d}(\mathrm{Iz}, \mathrm{z}) \leq \mathrm{f}(\mathrm{d}(\mathrm{Iz}, \mathrm{z}))
$$

which implies $\mathrm{I} z=z$ by $(\alpha \alpha \alpha)$.

Since

$$
\delta\left(F z, G y_{n}\right) \leq f\left(\max \left\{d\left(I z, J y_{n}\right), \delta\left(I z, G y_{n}\right), \delta\left(J y_{n}, F z\right)\right\}\right)
$$

we have on letting $n$ tend to infinity and using lemma 1 and property $(\alpha \alpha)$

$$
\delta(F z, z) \leq f(\delta(z, F z))
$$

which gives $\mathrm{Fz}=\{\mathrm{z}\}$ by $(\alpha \alpha \alpha)$.

Similarly, the weak commutativity of $G$ and $J$ and condition $\left(\lambda_{1}\right)$ implies $\mathrm{Jz}=\mathrm{z}$ and $\mathrm{Gz}=\{\mathrm{z}\}$.

Now assume that $\left(\gamma_{2}\right)$ holds. Then the sequence $\left\{\mathrm{FIx}_{\mathrm{n}}\right\}$ converges to $\mathrm{Fz}$ and using inequality $(2.3)$ we have

$$
\begin{aligned}
\delta\left(F I x_{n}, G y_{n}\right) & \leq \mathrm{f}\left(\max \left\{d\left(I^{2} x_{n}, J y_{n}\right), \delta\left(I^{2} x_{n}, G y_{n}\right), \delta\left(J y_{n}, F I x_{n}\right)\right\}\right) \\
& \leq \mathrm{f}\left(\max \left\{\delta\left(F I x_{n}, J y_{n}\right), \delta\left(F I x_{n}, G y_{n}\right), \delta\left(J y_{n}, F I x_{n}\right)\right\}\right)
\end{aligned}
$$

since $f$ is non-decreasing and $I x_{n}$ is in $F x_{n-1}$ and so $I^{2} x_{n}$ is in $I F x_{n-1} \subseteq F I x_{n-1}$. 
Letting $\mathrm{n}$ tend to infinity and using lemma 1 and property $(\alpha \alpha)$, we have

$\delta(F z, z) \leq f(\delta(F z, z))$

which implies $\mathrm{Fz}=\{z\}$ by $(\alpha \alpha \alpha)$. Thus by (2.1) there must exist a point $u$ in $X$ such that $\mathrm{Iu}=z$.

Using inequality (2.3) we have

$$
\delta\left(F u, G y_{n}\right) \leq f\left(\max \left\{d\left(I u, J y_{n}\right), \delta\left(I u, G y_{n}\right), \delta\left(J y_{n}, F u\right)\right\}\right) .
$$

Letting $n$ tend to infinity and using lemma 1 and property $(\alpha \alpha)$, we obtain the inequality

$$
\delta(F u, z) \leq f(\max \{d(I u, z), \delta(z, F u)\})=f(\delta(z, F u)) .
$$

Thus $F u=\{z\}$ by $(\alpha \alpha \alpha)$ and since $F$ and $I$ weakly commute, we have

$$
\{z\}=F z=F I u=I F u=\{I z\} \text {. }
$$

It follows that $I z=z$.

Similarly property $\left(\lambda_{2}\right)$ assures that $\mathrm{Gz}=\{z\}$ and $\mathrm{Jz}=z$.

We have therefore shown that if the conditions $\left(\gamma_{i}\right)$ and $\left(\lambda_{j}\right)$, with $i, j=1,2$, hold then $\mathrm{Iz}=\mathrm{Jz}=\mathrm{z}$ and $\mathrm{Fz}=\mathrm{Gz}=\{\mathrm{z}\}$.

That $z$ is the unique common fixed point of $F$ and $I$ and of $G$ and $J$ follows easily. This completes the proof of the theorem.

COROLLARY 1. Let $F, G$ be two set-valued mappings of $X$ into $B(X)$ and let $I, J$ be two selfmaps of $X$ satisfying (2.1) and

$$
\delta(F x, F y) \leqq c \cdot m a x\{d(I x, J y), \delta(I x, G y), \delta(J y, F x)\}
$$

for all $x, y$ in $x$, where $0 \leqq c<1$. Further, let $F$ and $G$ commute with $I$ and $J$ respectively. If $F$ or $I$ and $G$ or $J$ are continuous, then $F, G, I$ and $J$ have a unique common fixed point $z$. Further, $F z=G z=\{z\}$ and $z$ is the unique common fixed point of $F$ and $I$ and of $G$ and $J$.

PROOF. As in the proof of theorem 1 of [1], it is proved that (2.2) holds for any $x_{0}, y_{0}$ in $x$. Since $F$ and $G$ commute with $I$ and $J$ respectively, we have FIx $=I F x$ and $G J x=J G x$ for all $x$ in $x$. The thesis then follows from theorem 1 if we assume that $f(t)=c t$ for $a 11 t \geqq 0$.

The result of this corollary was given in [1].

We now give an example in which theorem 1 holds but corollary 1 is not applicable.

EXAMPLE 2. Let $X=[0,1]$ with $\delta$ induced by the euclidean metric $d$ and let $F x=[0, x /(x+4)], \quad G x=[0, x /(x+8)], \quad I x=J x=\frac{1}{2} x$ for all $x$ in $x$.

By example $1, F$ and $G$ weakly commute with $I$. Further, we have

$$
\begin{aligned}
& F(X)=[0,1 / 5] \subset\left[0, \frac{1}{2}\right]=I(X), \\
& G(X)=[0,1 / 9] \subset\left[0, \frac{1}{2}\right]=J(X), \\
& I F x=[0, x /(2 x+8)] \subset[0, x /(x+8)]=F I x \\
& J G x=[0, x /(2 x+16)] \subset[0, x /(x+16]=G J x
\end{aligned}
$$

for all $x$ in $x$.

Since

$$
\begin{aligned}
\delta(F x, \text { Gy }) & =\max \{x /(x+4), y /(y+8)\} \\
& \leq \max \{x /(x+4), y /(y+4)\}
\end{aligned}
$$




$$
\begin{aligned}
& \leq \frac{1}{2} \max \left\{\frac{1}{2} \mathrm{x}, \frac{1}{2} \mathrm{y}\right\} \\
& = \begin{cases}\frac{1}{2} \delta(\mathrm{Ix}, \mathrm{Gy}), & \text { if } \mathrm{x} \geq \mathrm{y}, \\
=\frac{1}{2} \delta(\mathrm{Jy}, \mathrm{Fx}), & \text { if } \mathrm{x}<\mathrm{y}\end{cases}
\end{aligned}
$$

and since $X$ is bounded all the hypotheses of theorem 1 are satisfied if we assume $f(t)=\frac{1}{2} t$ for all $t \geq 0$. Clearly $f$ is in $F$ and 0 is the unique common fixed point of $F, G$ and $I$.

Theorem 1 is a stronger result than corollary l, even if the mappings under consideration are commutative, as is shown in the following example.

EXAMPLE 3. Let $X$ be the reals with $\delta$ induced by the euclidean metric $d$, let

$$
\begin{gathered}
F x=\left\{\begin{array}{cl}
\{0\}, & \text { if } x \leq 0, \\
{[0, x /(1+3 x)],} & \text { if } 0<x \leq 1, \\
{[0,1 / 4],} & \text { if } x>1
\end{array}\right. \\
G x=\left\{\begin{array}{cl}
\{0\}, & \text { if } x \leq 0, \\
{[0, x /(1+2 x)],} & \text { if } 0<x \leq 1, \\
\{1 / 3\}, & \text { if } x>1,
\end{array}\right. \\
I x=\left\{\begin{array}{c}
0, \text { if } x \leq 0, \\
x, \text { if } 0<x \leq 1, \\
1, \text { if } x>1,
\end{array}\right.
\end{gathered}
$$

for all $x$ in $X$ and let $f$ in $F$ be given by

We have

$$
f(t)= \begin{cases}t /(1+2 t), & \text { if } 0 \leq t \leq 1, \\ t / 3, & \text { if } t>1 .\end{cases}
$$

$$
\begin{aligned}
& \delta(F x, G y)=0=f(d(I x, J y)) \text {, if } x, y \leq 0 \text {, } \\
& \delta(\mathrm{Fx}, \mathrm{Gy})=\mathrm{y} /(1+2 \mathrm{y})=\mathrm{f}(\mathrm{y})=\mathrm{f}(\mathrm{d}(\mathrm{Ix}, \mathrm{Jy})) \text {, if } \mathrm{x} \leq 0 \text { and } 0<\mathrm{y} \leq 1 \text {, } \\
& \delta(\mathrm{Fx}, \mathrm{Gy})=1 / 3<\mathrm{y} / 3=\mathrm{f}(\mathrm{y})=\mathrm{f}(\mathrm{d}(\mathrm{Ix}, \mathrm{Jy})) \text {, if } \mathrm{x} \leq 0 \text { and } \mathrm{y}>1 \text {, } \\
& \delta(\mathrm{Fx}, \mathrm{Gy})=\mathrm{x} /(1+3 \mathrm{x})<\mathrm{x} /(1+2 \mathrm{x})=\mathrm{f}(\mathrm{x})=\mathrm{f}(\mathrm{d}(\mathrm{Ix}, \mathrm{Jy})) \text {, if } 0<\mathrm{x} \leq 1 \text { and } \mathrm{y} \leq 0 \text {, } \\
& \delta(F x, G y)=\max \{x /(1+3 x), y /(1+2 y)\} \\
& <\max \{x /(1+2 x), y /(1+2 y)\} \\
& = \begin{cases}\mathrm{f}(\mathrm{y})=\mathrm{f}(\delta(\mathrm{Fx}, \mathrm{Jy})), & \text { if } \mathrm{x} \leq \mathrm{y}, \\
\mathrm{f}(\mathrm{x})=\mathrm{f}(\delta(\mathrm{Ix}, \mathrm{Gy})), & \text { if } \mathrm{x}>\mathrm{y}, \text { and if } 0<\mathrm{x}, \mathrm{y} \leq 1,\end{cases} \\
& \delta(F x, G y)=1 / 3<y / 3=f(y)=f(\delta(J y, F x)) \text {, if } 0<x \leq 1 \text { and } y>1 \text {, } \\
& \delta(\mathrm{Fx}, \mathrm{Gy})=1 / 4<1 / 3=\mathrm{f}(1)=\mathrm{f}(\mathrm{d}(\mathrm{Ix}, \mathrm{Jy})) \text {, if } \mathrm{x}>1 \text { and } \mathrm{y} \leq 0 \text {, } \\
& \delta(\mathrm{Fx}, \mathrm{Gy})=\max \{1 / 4, \mathrm{y} /(1+2 \mathrm{y})\} \leq 1 / 3=\mathrm{f}(1)=\mathrm{f}(\delta(\mathrm{Ix}, \mathrm{Gy})) \text {, if } \mathrm{x}>1 \text { and } \\
& \delta(\mathrm{Fx}, \mathrm{Gy})=1 / 3<\mathrm{y} / 3=\mathrm{f}(\mathrm{y})=\mathrm{f}(\delta(\mathrm{Jy}, \mathrm{Fx})) \text {, if } \mathrm{x}, \mathrm{y}>1 .
\end{aligned}
$$

Condition (2.3) therefore holds in every case since $f$ is non-decreasing. Further

$$
\begin{aligned}
& F(X)=[0,1.4] \subset[0,1]=I(X), \\
& G(X)=[0,1 / 3] \subset[0, \infty]=J(X)
\end{aligned}
$$

and $F$ and $G$ commute with $I$ and $J$ respectively. Since $F x \subseteq[0,1 / 4]$ and $G x \subseteq[0,1 / 3]$ for all $x$ in $X$, it is easily seen that $M \leq 1 / 3$ and so (2.2) holds for any $x_{0}$ and $y_{0}$ chosen in $x$. As $I$ and $J$ are continuous, theorem 1 is applicable. However, the conditions of the corollary are not satisfied. Otherwise for $x=0$ and $0<y \leq 1$, condition (2.4) should imply 
$\delta(F x, G y)=\frac{y}{1+2 y} \leq c \cdot \max \left\{y, \frac{y}{1+2 y}, y\right\}=c y$
and so $1 /(1+2 y) \leq c$ which as $y$ tends to zero, gives $c \geq 1$, a contradiction.

\section{REFERENCES}

1. FISHER, B., "Common fixed point theorems for mappings and set-valued mappings", J. Univ. Kuwait Sci., to appear.

2. FISHER, B., "Common fixed points of mappings and set-valued mappings", Rostock. Math Kollog., 18 1981$), 69-77$.

3. SESSA, S., KHAN, M.S., and IMDAD, M., "Common fixed point theorems with a weak commutativity condition", submitted for publication.

4. FISHER,B., "Fixed points of mappings and set-valued mappings", J. Univ. Kuwait Sci., $\underline{9}(1982), 175-180$.

5. SESSA, S., "On a weak commutativity condition in fixed point considerations", Publ. Inst. Math., $32(46)(1982), 149-153$.

6. BARCZ, E. "Some fixed point theorems for multi-valued mappings", Demonstratio Math., $16(1983), 735-744$.

7. CHEN, M. P. and SHIN, M. H., "Fixed point theorems for point to point and point to set maps", J. Math. Ana1. App1., 71 (1979), 515-524.

8. GUAY, M.D., SINGH, K. L., and WHITFIELD, J.H.M., "Common fixed points for set-valued mappings", Bull. Acad. Polon. Sci. Sér. Sci. Math., 30(1982), 545-551.

9. MICZKO, A. and PALCZEWSKI, B., "On convergence of successive approximations of some generalized contraction mappings", Ann. Polon. Math., 4 (1983), 213-232.

10. DUANG TRONG NHAN, "Pair of nonlinear contraciton mappings common fixed points", Studia Univ. Babes-Bolyai Math., 26 (1981), 34-51.

11. PAPAGEORGIOU, N. S., "Fixed point theorems for multifunctions in metric and vector spaces", Nonlinear Anal. TMA 7 (1983), 763-770.

12. POPA, V., "Fixed point theorems for multifunctions", Studia Univ. Babes-Bolyai Math., $\underline{27}(1982), 21-27$.

13. SHARMA, A. K., "Common fixed points of set-valued maps", Bull. Acad. Polon. Sci. Sér. Sci. Math., 27(1979), 407-412.

14. WEGRZYK, R., "Fixed-point theorems for multi-valued functions and their applications to funcitonal equations", Dissertations Math., 201, Warszawa (1982), 1-28.

15. SINGH, S.P. and MEADE, B.A.,"On common fixed point theorems", Bull. Austral. Math. Sco., 16 (1977), 49-53.

16. BENEDYKT, Z, and MATKOWSKI, J., "Remarks on fixed point theorems", Demonstratic Math., 14 1981$), 227-232$.

i7. BROWDER, F. E., "Remarks on fixed point theorems of contractive type", Nonlinear Ana1. TMA, 3 (1979), 657-661.

18. CONSERVA, V. and FEDELE, F., "Remark on a Browder's fixed point theorem", Math. Japon., 28 (1983), 147-157.

19. HEGEDÜS, M. and SZILÁGYI, T., "Equivalent conditions and a new fixed point theorem in the theory of contractive type mappings", Math. Japon., 25(1980), 147-157.

20. HIKIDA, M., "A note on contractions in ranked space", Math. Japon., 26(1981), 131137.

21. PARK, S. and RHOADES, B. E., "Extensions of some fixed point theorems of Hegedüs and Kasahara", Math. Sem. Notes, Kobe Univ., 9(1981), 113-118.

22. RHOADES, B. E., "Contractive definitions revisited", Topological Methods in Nonlinear Functional Analysis, Contemporary Math. AMS, 21 (1983), 189-205.

23. SINGH, S. L. and KASAHARA, S., "On some recent results on common fixed points", Indian J. Pure App1. Math., 13 (7) (1982), 757-761.

24. FISHER, B., "Four mappings with a common fixed point", J. Univ. Kuwait Sc1., $\underline{8}(1981)$, $131-139$. 


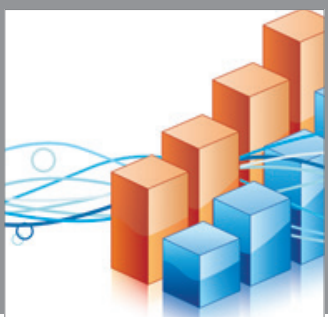

Advances in

Operations Research

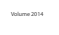

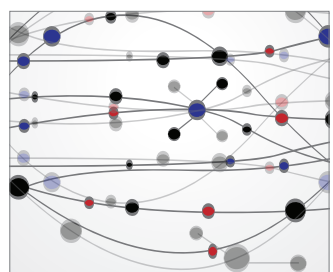

\section{The Scientific} World Journal
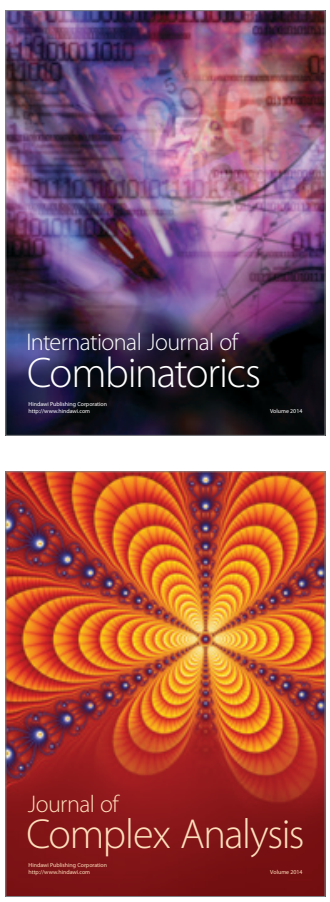

International Journal of

Mathematics and

Mathematical

Sciences
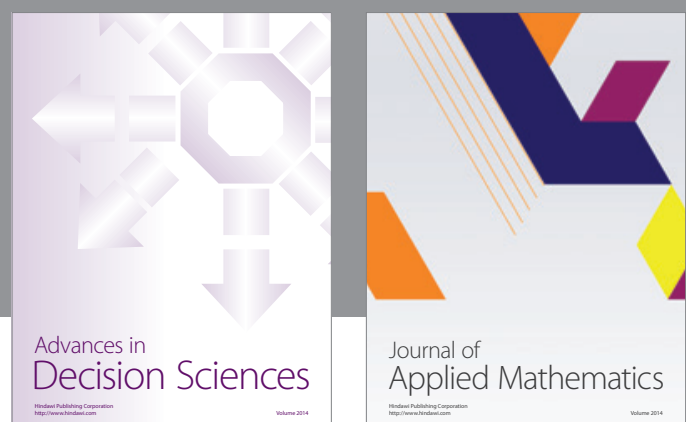

Journal of

Applied Mathematics
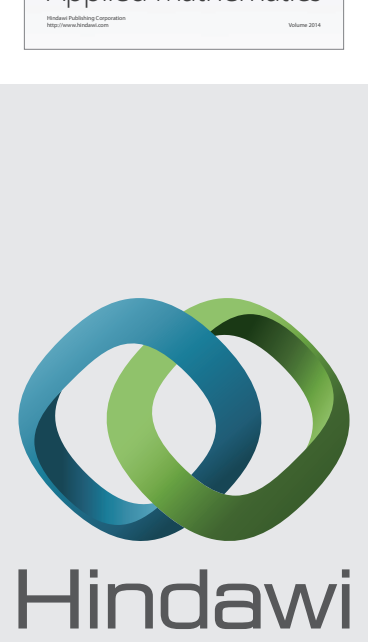

Submit your manuscripts at http://www.hindawi.com
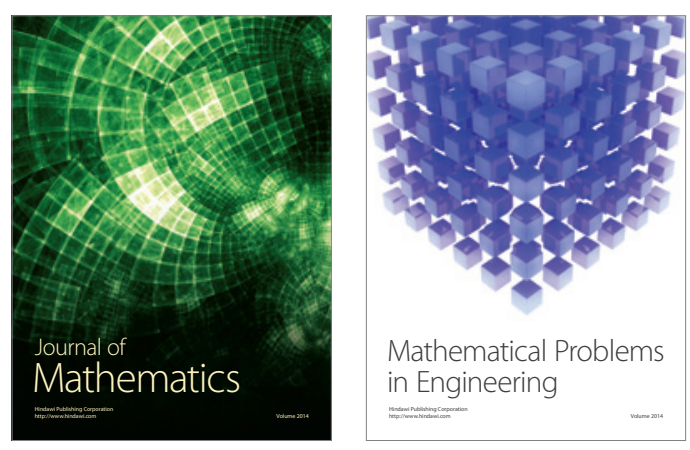

Mathematical Problems in Engineering
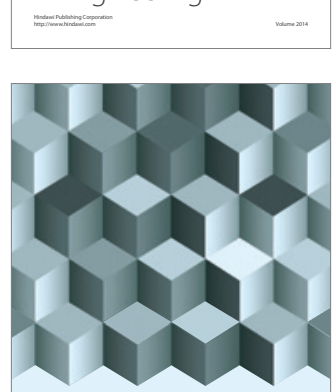

Journal of

Function Spaces
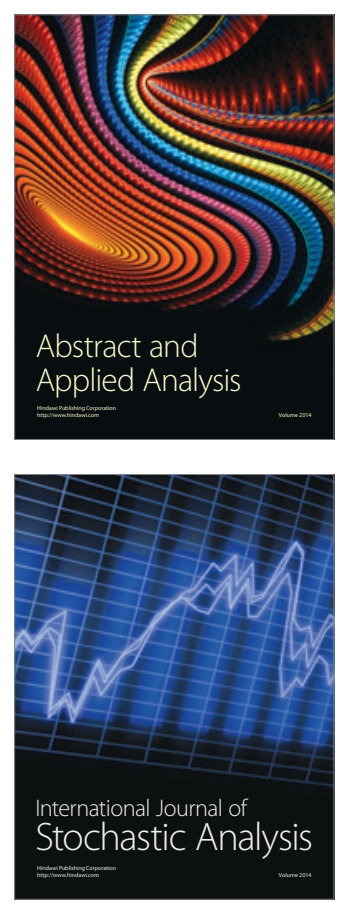

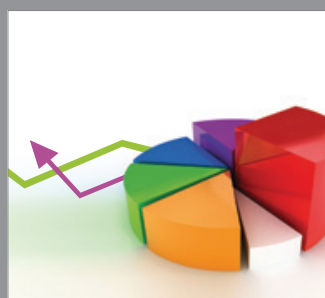

ournal of

Probability and Statistics

Promensencen
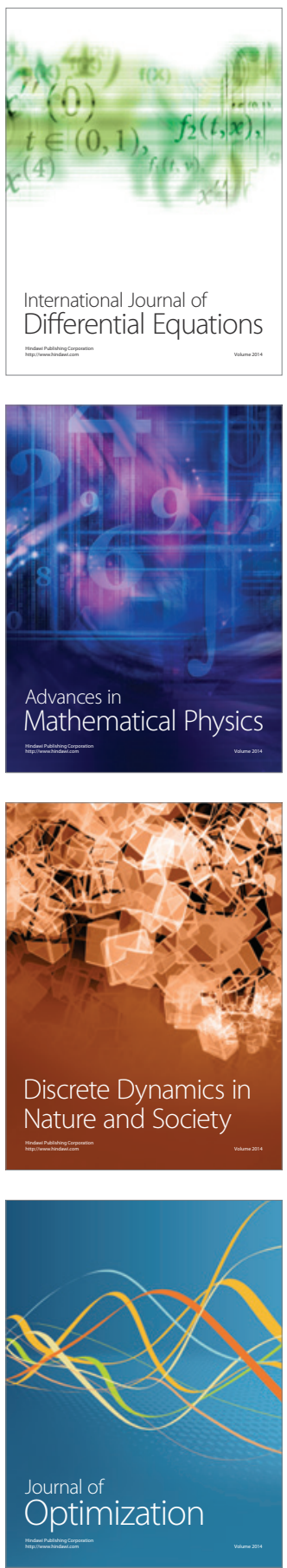